\title{
Sektion B
}

Forum $2021 \cdot 36: 317$

https://doi.org/10.1007/s12312-021-00949-6

Online publiziert: 28. Juni 2021

○) Springer Medizin Verlag $\mathrm{GmbH}$, ein Teil von

Springer Nature 2021

\section{Die Aufforderung der Krankenkasse zum Antrag auf Rehabilitation verstehen}

\author{
Arbeitshilfe für Sozialdienste und ambulante \\ Beratungsstellen zur Problematik des §51 SGB V
}

Arbeitsgemeinschaft Soziale Arbeit in der Onkologie (ASO) der DKG in Zusammenarbeit mit dem Krebsinformationsdienst KID am DKFZ Heidelberg und Leben nach Krebs!
Im Auftrag der Arbeitsgemeinschaft Soziale Arbeit in der Onkologie (ASO) in der DKG ist in Zusammenarbeit mit dem Krebsinformationsdienst KID am DKFZ Heidelberg und Leben nach Krebs! e.V. die Arbeitshilfe „Die Aufforderung der Krankenkasse zum Antrag auf Rehabilitation verstehen" entstanden. Sie richtet sich an Sozialdienste und ambulante Beratungsstellen zur Problematik des $\S 51$ SGB V.

Folgende Inhalte greift die Broschüre auf:

- Rechtliche, finanzielle und psychosoziale Konsequenzen für Betroffene

- Das Verfahren - Schritt für Schritt.

- Kompaktübersicht über das Verfahren

- Fallbeispiele aus der Beratungspraxis

- Textbausteine und Formulierungshilfen für den Widerspruch

Die Broschüre steht zum Download auf https://www.krebsgesellschaft.de/arbeitsgemeinschaften/aso.html zur Verfügung.

\section{Korrespondenzadresse}

Deutsche Krebsgesellschaft e.V.

Kuno-Fischer-Straße 8, 14057 Berlin, Deutschland

service@krebsgesellschaft.de

www.krebsgesellschaft.de

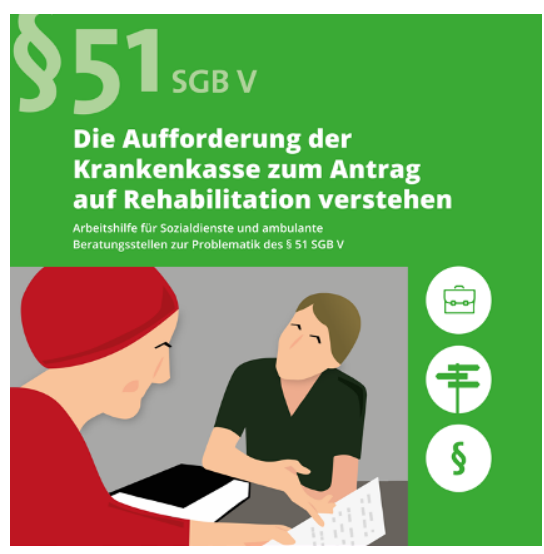

Die Aufforderung der

Krankenkasse zum Antrag

auf Rehabilitation verstehen

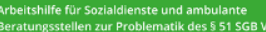

